\title{
Experimental Investigation of Seismic-Induced Hydrodynamic Pressures on a Vertical Wall under Conditions of Wave Resonance
}

\author{
YiLiang Zhou, ${ }^{1}$ LingKan Yao, ${ }^{1,2,3}$ MingYuan Gao, ${ }^{1}$ and Hongzhou Ai ${ }^{1}$ \\ ${ }^{1}$ School of Civil Engineering, Southwest Jiaotong University, Chengdu, Sichuan 610031, China \\ ${ }^{2}$ MOE Key Laboratory of High-Speed Railway Engineering, Southwest Jiaotong University, Chengdu, Sichuan 610031, China \\ ${ }^{3}$ National Engineering Laboratory for Technology of Geological Disaster Prevention in Land Transportation, Chengdu 610031, China
}

Correspondence should be addressed to LingKan Yao; yaolk@swjtu.edu.cn

Received 20 April 2017; Revised 18 July 2017; Accepted 31 July 2017; Published 6 September 2017

Academic Editor: Hugo Rodrigues

Copyright (C) 2017 YiLiang Zhou et al. This is an open access article distributed under the Creative Commons Attribution License, which permits unrestricted use, distribution, and reproduction in any medium, provided the original work is properly cited.

The distribution of hydrodynamic pressure acting on the structural face of a dam significantly influences the stability of the dam. The present study investigates the development of the hydrodynamic pressure acting on the surface of a dam at different heights with respect to time during earthquakes with different dominant frequencies using a shaking table. The results demonstrate that the variation in the hydrodynamic pressure significantly follows the seismically accelerated wave motion in the absence of resonance. However, under conditions of resonance, the fluctuations in the hydrodynamic pressure exhibit similarities with a sine wave, and the positive peak values present some hysteresis. The experimental pressure values in the absence of resonance present parabolic distributions with respect to the water height that are in good agreement with the corresponding hydrodynamic pressures determined by Westergaard's equation, while conditions of wave resonance produce a uniform distribution of hydrodynamic pressures with greater values and much longer periods of increased hydrodynamic pressure than the case of nonresonance. In addition, the seismic frequency, fundamental frequency of the reservoir, maximum peak seismic acceleration, and initial water depth are treated as variables. An empirical equation is derived to predict the maximum hydrodynamic pressure in conjunction with wave resonance conditions.

\section{Introduction}

The motion of seismic-induced hydraulic structures can generate considerable hydrodynamic pressure on the structural face of a dam, which can significantly affect its stability. Westergaard [1] first derived an expression for the hydrodynamic pressure exerted on the vertical upstream face of a concrete dam subjected to a single harmonic excitation. In fact, many current engineering designs have continued to employ a simplified form of this formula to account for hydrodynamic pressure loads [2-4]. In 1953, Zangar [5] developed an experimental solution for the same problem using an electrical analogue and reported extensive results for a variety of nonvertical upstream faces. Chwang and Housner $[6,7]$ solved the hydrodynamic pressure problem for a more general dam configuration using the momentum method and two-dimensional (2D) potential flow theory, respectively.
Wang et al. [8] modified Westergaard's equation by considering the influence of dam height, elasticity, and reservoir bottom condition. The results generated by these works were more or less equivalent to the results of Westergaard.

Numerous researchers have studied hydrodynamic pressure under seismic excitation using a variety of other methods to consider the effects of different parameters. Saini et al. [9] employed the finite element method to analyze the 2D response of a reservoir-dam system subjected to horizontal ground motion. When the water was assumed to be incompressible, its effect on the dam was found to be equivalent to that of an added mass. When the water was assumed to be compressible, its effect was found to be equivalent to that of an added mass in conjunction with added damping. Moreover, the coupled response of the system was significantly increased relative to the uncoupled response at the fundamental natural frequency of the system. Zingales [10] 
analyzed the hydrodynamic pressure in a dam-reservoir system with an infinite reservoir composed of a compressible fluid and modeled seismic acceleration as a normal zeromean stochastic process. Based on the results, the close relationship between the frequency content of the seismic vibrations and the seismic-induced hydrodynamic pressure was outlined. Bouaanani et al. [11] considered water compressibility and wave absorption at the reservoir bottom to establish closed-form formulas for solving the fluid-dam interaction problem. Gogoi and Maity [12] conducted seismic excitation analysis based on the short-time Fourier transform to evaluate hydrodynamic pressures along the upstream face of a dam-reservoir system. Chen and Malenica [13] examined the distributions of hydrodynamic pressure on the surface of a ship hull for a large range of encounter frequencies. Saleh and Madabhushi [14, 15] investigated the effect of dam-foundation interaction on the hydrodynamic pressure response on a dam face under different seismic excitations using the dynamic centrifuge modeling technique. This work proposed an experimental method for examining hydrodynamic pressure. Pelecanos et al. $[16,17]$ employed numerical modeling to investigate the hydrodynamic pressures of stiff and flexible dams with vertical and sloped upstream faces under ramp, harmonic, and random acceleration loads and further examined the elastic dynamic response of dams. Xu et al. [18] employed a semianalytical scaled boundary finite element method (SBFEM) to investigate the hydrodynamic pressure acting on the concrete face slabs of rockfill dams. In addition, Chen and Yuan [19] studied nonlinear hydrodynamic pressures with consideration for the influence of vertical seismic waves.

As can be seen from the above discussion, considerable efforts have been made to investigate seismic-induced hydrodynamic pressure on dam faces. However, thus far, few experimental studies have examined the development of seismic-induced hydrodynamic pressures with respect to time in conjunction with wave resonance. Therefore, the present study simulated actual seismic waves using a shaking table, and experiments were accordingly conducted to investigate the characteristics of the seismic hydrodynamic pressure acting on the wall. Use of the shaking table allowed the acceleration amplitude and frequency of waves to be finely controlled. In each experimental test, the pressures exerted by the water were recorded by sensors attached to the wall at various water heights. Here, the additional seismic-induced water pressure acting on the wall is regarded as the seismic hydrodynamic pressure. Then, the effects of main parameters such as seismic frequency, maximum peak seismic acceleration, the fundamental frequency of the reservoir, and initial water depth are considered in the analysis of the results. An empirical equation is established for evaluating seismic hydrodynamic pressure in conjunction with wave resonance.

\section{Shaking Table Experiments}

2.1. Experimental Setup. The present experimental setup consists of six components: a shaking platform, vibrator, hydraulic pumps, control system, water tank, and water pressure acquisition system, as illustrated in Figure 1. The platform was $4 \mathrm{~m} \times 2 \mathrm{~m}$ and accommodated a maximum payload of $25 \mathrm{t}$. The water tank was installed on the platform and had a length of $3.76 \mathrm{~m}$, a width of $1.76 \mathrm{~m}$, and a height of $1.50 \mathrm{~m}$. The water body (i.e., the actual reservoir within the water tank) had a length of $2.73 \mathrm{~m}$, a width of $1.76 \mathrm{~m}$, and a depth of $0.35 \mathrm{~m}$. To simulate the excitation of an earthquake during tests, the water body was subjected to movement in a single direction along its length using hydraulic pumps. The motion induced after which the vibrator received the signal and the hydraulic pumps caused the platform and water tank to shake. The frequency of the shaking table ranged from $0.4 \mathrm{~Hz}$ to $15 \mathrm{~Hz}$, with a corresponding maximum amplitude of $100 \mathrm{~mm}$ and a maximum acceleration of $1.2 \mathrm{~g}$, where $g$ is the acceleration due to gravity. Prior to each experimental test, the input accelerated wave motion was calibrated to ensure accurate experimental measurements. The input accelerated seismic wave was firstly designed using a digital control system, and then the actual shaking table waveform obtained by the vibrator based on the designed waveform was compared with the designed waveform for feedback correction and iterative optimization to ensure a good match. The final optimized signal obtained was then applied for driving the shaking table during experiments. Six pulsating water pressure sensors were attached to the vertical wall for measuring the hydrodynamic pressures at a frequency of $500 \mathrm{~Hz}$. The pulsating water pressure sensors employed have a range of $-100 \mathrm{kPa}$ to $100 \mathrm{kPa}$ and an accuracy of $0.1 \%$. The sensors were numbered as P1 to P6, with corresponding heights from the reservoir bottom of $2 \mathrm{~cm}$, $8 \mathrm{~cm}, 14 \mathrm{~cm}, 20.5 \mathrm{~cm}, 27.5 \mathrm{~cm}$, and $31.5 \mathrm{~cm}$, respectively. A detailed illustration of the sensor positions is presented in Figure 2.

2.2. Experimental Design. To analyze the seismic-induced hydrodynamic pressure in conjunction with wave resonance, we firstly obtained the resonant frequency of the water body. According to the study of Saini et al., the hydrodynamic pressure response is significantly reduced at resonant frequencies higher than the fundamental resonant frequency [9]. Therefore, the present study considered only the fundamental natural frequency of the water body (i.e., the reservoir). The analytical formula generally employed for defining the natural angular frequencies of a reservoir in a single direction is expressed as follows [20-22]:

$$
\omega_{n}^{2}=\frac{n g \pi}{L} \tanh \left(\frac{n \pi h}{L}\right) \quad n=(1,3,5, \ldots),
$$

where $L$ is the length of the reservoir and $h$ is the depth of the reservoir. The fundamental natural frequency in the single direction $L$ of the reservoir employed for testing is then

$$
\begin{aligned}
f_{1} & =\frac{\omega_{1}}{2 \pi} \\
& =\frac{\sqrt{((9.8 \times 3.14) / 2.73) \times \tanh ((3.14 \times 0.35) / 2.73)}}{(2 \times 3.14)} \\
& =0.33 \mathrm{~Hz} .
\end{aligned}
$$




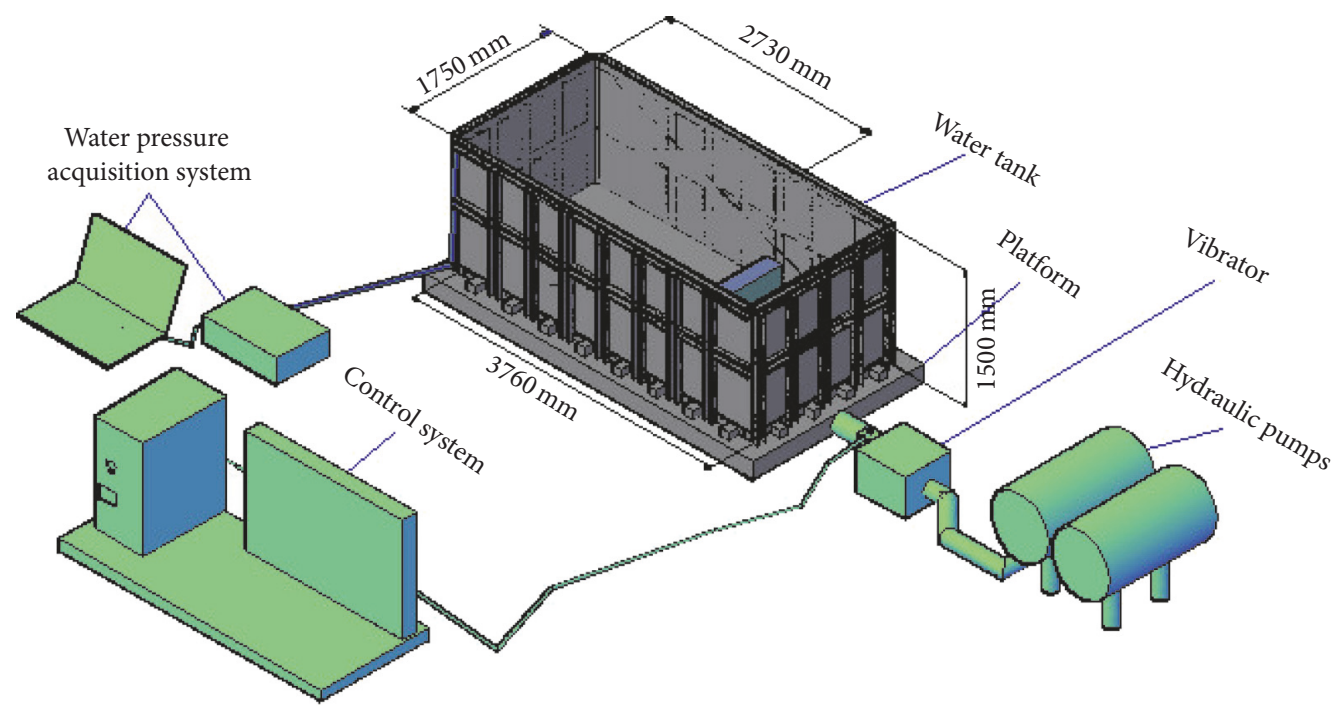

FIGURE 1: A typical illustration of the experimental setup design.
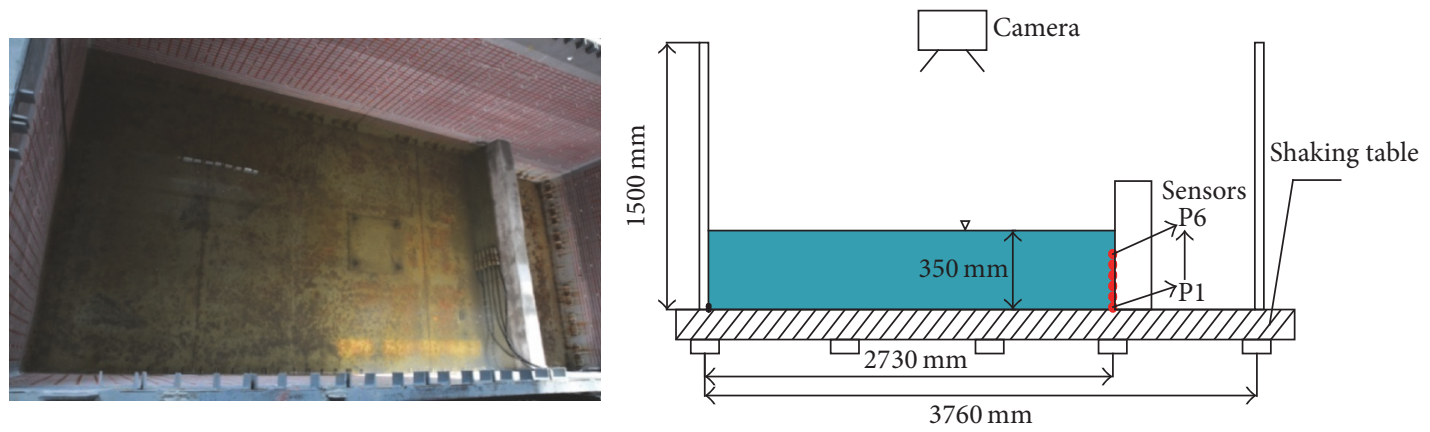

FIGURE 2: Image and schematic diagram of the pulsating water pressure sensor positions.

White noise was then employed as the signal source to test the resonant frequency of the reservoir. A fast Fourier transform (FFT) analysis of the measured water pressure caused by the white noise signal is presented in Figure 3, which shows that the measured fundamental natural frequency was $0.3325 \mathrm{~Hz}$, which is in good agreement with the theoretical prediction. The presented formula therefore provides an effective method for calculating the fundamental natural frequency of a reservoir in the absence of actual measured data.

Two different seismic waves were utilized to compare the development of the hydrodynamic pressure at various heights with respect to time for conditions both with and without wave resonance. One seismic waveform was modeled according to the Wenchuan Ms 8.0 earthquake that transpired on May 12, 2008, in Wolong, China, which exhibited a dominant frequency of $2.35 \mathrm{~Hz}$ (denoted herein as EQ1). The second seismic waveform was modeled according to the MexicaliCalifornia Ms 7.2 earthquake that transpired on April 4, 2010, which exhibited a dominant frequency of $0.38 \mathrm{~Hz}$ (denoted herein as EQ2). These seismic waveforms are presented in Figures 4 and 5, respectively. Here, we note that the dominant

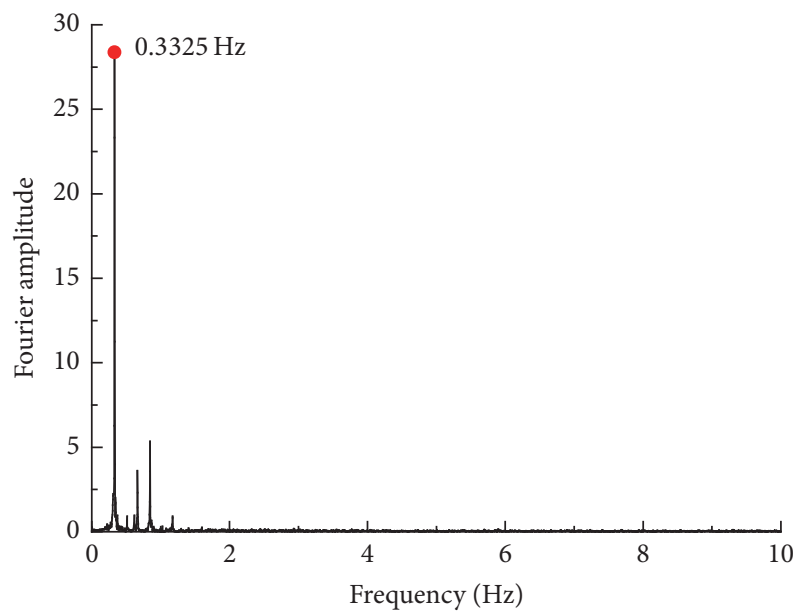

FIGURE 3: Fourier amplitude spectrum of the hydrodynamic pressure of the reservoir employed in the tests due to white noise excitation.

frequency of EQ2 is close to the fundamental natural frequency of the water body, whereas the dominant frequency of 


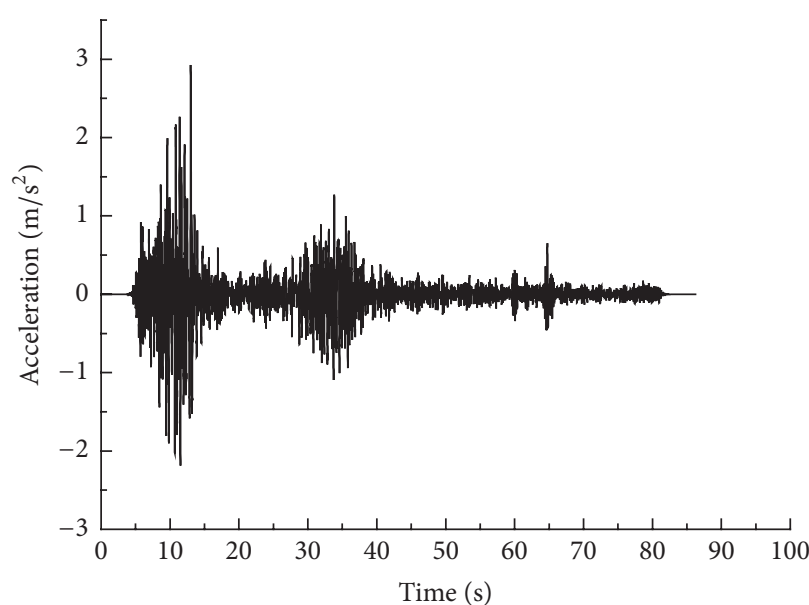

(a) Time-domain acceleration response curve due to the Wolong earthquake waveform

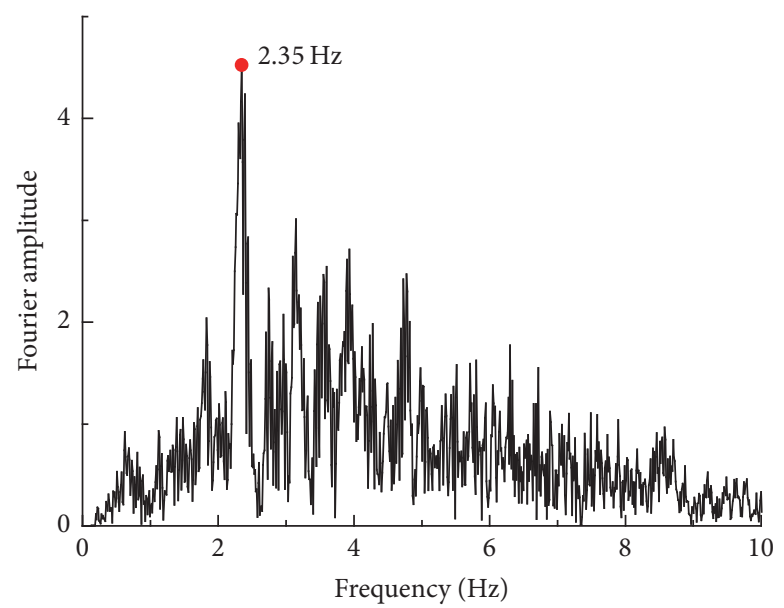

(b) Fourier amplitude spectrum of the Wolong earthquake waveform

FIGURE 4: Seismic parameters of the Wolong earthquake waveform (EQ1).

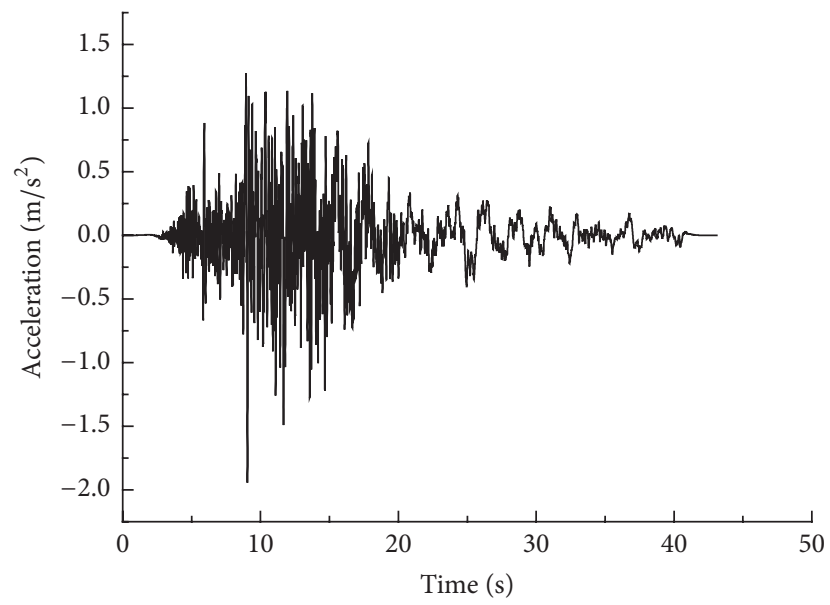

(a) Time-domain acceleration response curve due to the Mexicali earthquake waveform

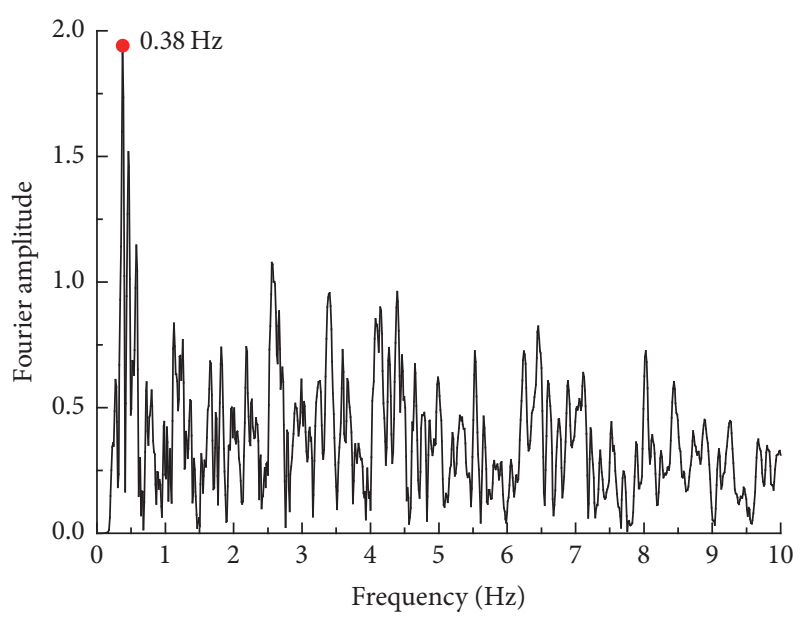

(b) Fourier amplitude spectrum of the Mexicali earthquake waveform

FIGURE 5: Seismic parameters of the Mexicali earthquake waveform (EQ2).

EQ1 is much greater than the fundamental natural frequency. The details of the experimental seismic waves and the corresponding peak ground acceleration (PGA) are presented in Table 1. In each test, the modeled seismic waveform was applied to the shaking table, and the hydrodynamic pressures at the corresponding heights were recorded by the water pressure acquisition system with respect to time. Following the completion of the seismic waveform, the acquisition system continued operation until the entire water body had achieved a calm state. The water pressure values obtained for the individual sensors prior to testing were subtracted from the hydrodynamic pressures obtained during earthquake simulation at the corresponding heights. Therefore, both the pressure caused by seismic-induced free surface waves and the pressure caused by dynamic interaction between the
TABLE 1: Seismic waveforms employed in testing and their peak ground acceleration (PGA).

\begin{tabular}{lcccccc}
\hline $\begin{array}{l}\text { Seismic } \\
\text { waveform }\end{array}$ & \multicolumn{6}{c}{ Seismic peak ground acceleration $\left(\mathrm{m} / \mathrm{s}^{2}\right)$} \\
\hline $\begin{array}{l}\text { Wolong wave } \\
\text { (EQ1) }\end{array}$ & $0.05 \mathrm{~g}$ & $0.1 \mathrm{~g}$ & $0.15 \mathrm{~g}$ & $0.2 \mathrm{~g}$ & $0.25 \mathrm{~g}$ & $0.3 \mathrm{~g}$ \\
$\begin{array}{l}\text { Mexicali wave } \\
\text { (EQ2) }\end{array}$ & $0.05 \mathrm{~g}$ & $0.1 \mathrm{~g}$ & $0.15 \mathrm{~g}$ & $0.2 \mathrm{~g}$ & $0.25 \mathrm{~g}$ & $0.3 \mathrm{~g}$ \\
\hline
\end{tabular}

water body and the sidewall during earthquake simulation may be included in the recorded hydrodynamic pressures. We did not fractionize the components of the seismic-induced water pressure. 


\section{Experimental Results and Discussion}

3.1. Hydrodynamic Pressure in the Absence of Wave Resonance. Figure 6 presents the hydrodynamic pressures recorded by sensors P1-P6 (i.e., from the bottom to the top of the water body) during simulation of the EQ1 waveform. In addition, the $0.25 \mathrm{~g}$ acceleration results are also presented.

Generally, the synchronized hydrodynamic pressures obtained at $\mathrm{P} i$, where $i=1,2,3,4,5,6$, in Figure 6 yield similar values. However, the variation in the hydrodynamic pressure with respect to time measured near the surface by P6 differed somewhat from the pressures measured by the other sensors because the pressure at P6 was also strongly affected by the surface wave. Therefore, the hydrodynamic pressures measured near the bottom by P1 were selected for analyzing the variation in the hydrodynamic pressure acting on the wall with respect to time. The development of the hydrodynamic pressures at various water heights with respect to time can be divided into two main stages based on the red broken vertical line shown in Figure 6 for P1. For $0<t<83 \mathrm{~s}$, (a) the hydrodynamic pressures vary significantly following the seismically accelerated wave motion. For $t>83 \mathrm{~s}$, (b) the hydrodynamic pressure returns to zero after the completion of seismic excitation. We note that the employment of an excitation frequency far from the fundamental frequency of the water body resulted in the synchronization between the seismic acceleration wave response and the hydrodynamic pressure response, such that the hydrodynamic pressure was mainly affected by the amplitude of the seismic acceleration.

A comparison between the maximum experimental hydrodynamic pressures on the wall and the values theoretically determined by the Westergaard formula is presented in Figure 7. The sensor heights $y$ have been normalized with respect to the reservoir depth $h$ and the maximum hydrodynamic pressures $P_{\max }(y)$ have been normalized with respect to the total hydrostatic pressure $\rho g h$, where $\rho$ is the unit density of water $\left(1.0 \mathrm{t} / \mathrm{m}^{3}\right)$. Generally, the formulas developed by Westergaard and others were derived based on a simple harmonic wave, which differs from actual seismic waves that consist of a continuum of harmonic waves. However, the results presented in Figure 6 indicate that the variation in the hydrodynamic pressure significantly follows the seismically accelerated wave motion well, and, clearly, the peak acceleration of the seismic excitation corresponds with the maximum hydrodynamic pressure. Therefore, the maximum hydrodynamic pressures generated by EQ1 can be calculated by Westergaard's formula using the corresponding seismic peak acceleration. And according to Figure 7, the maximum hydrodynamic pressure increases monotonically with respect to the seismic acceleration, and the measured values match well with the hydrodynamic pressure calculated by Westergaard's formula. It is evident that Westergaard's approximate formula appropriately predicts the hydrodynamic pressures in the absence of wave resonance.

\subsection{Hydrodynamic Pressure with Wave Resonance. As was} found for EQ1, the hydrodynamic pressures obtained at different heights along the wall during the simulated Mexicali earthquake waveform (EQ2) exhibited similar values with
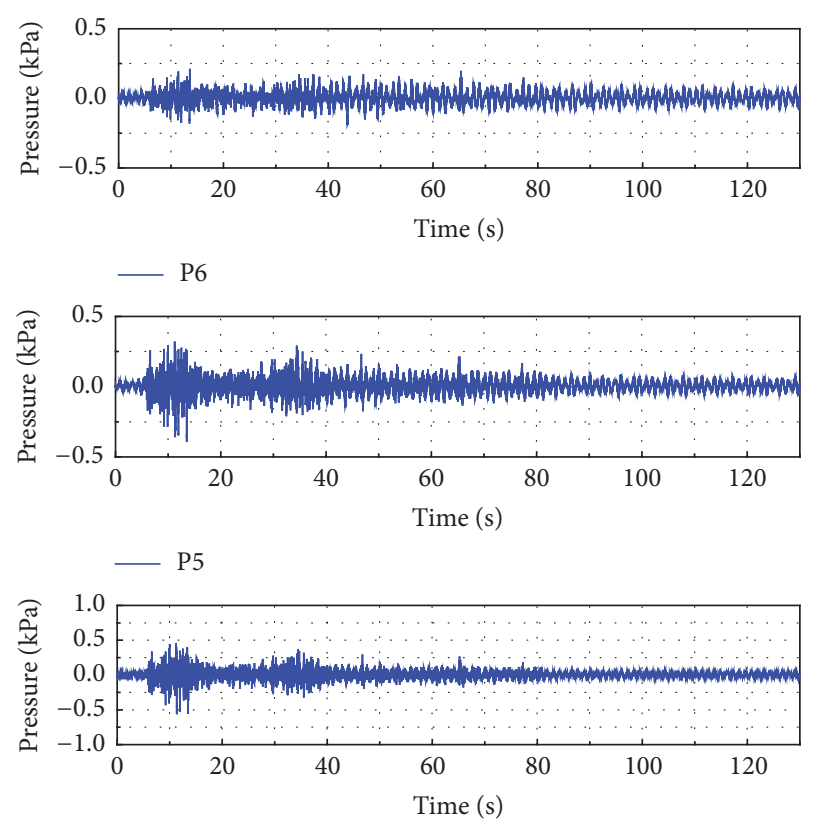

$-\mathrm{P} 4$
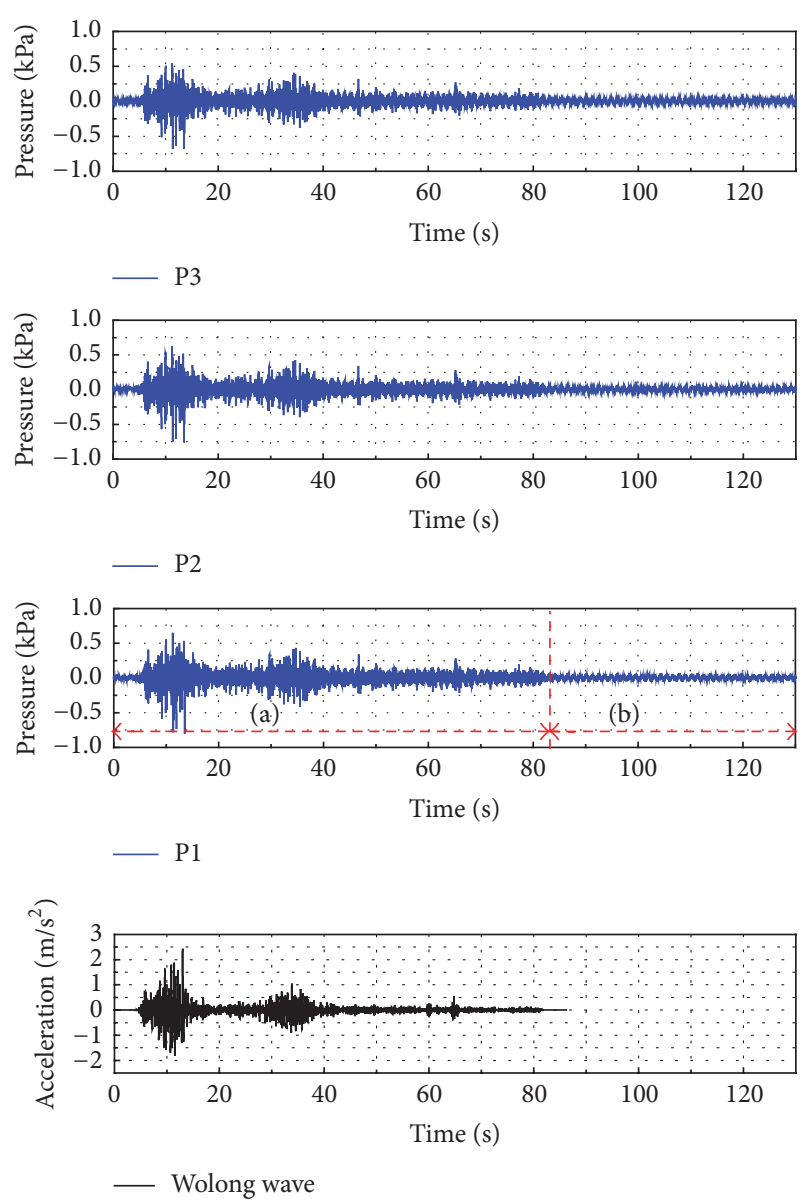

FIGURE 6: Fluctuations in the hydrodynamic pressures at sensors P1-P6 and the $0.25 \mathrm{~g}$ acceleration results with respect to time due to the Wolong earthquake waveform (EQ1).

respect to time. As discussed earlier, the pressure recorded at P6 was also affected between the sensor and the surface wave. 


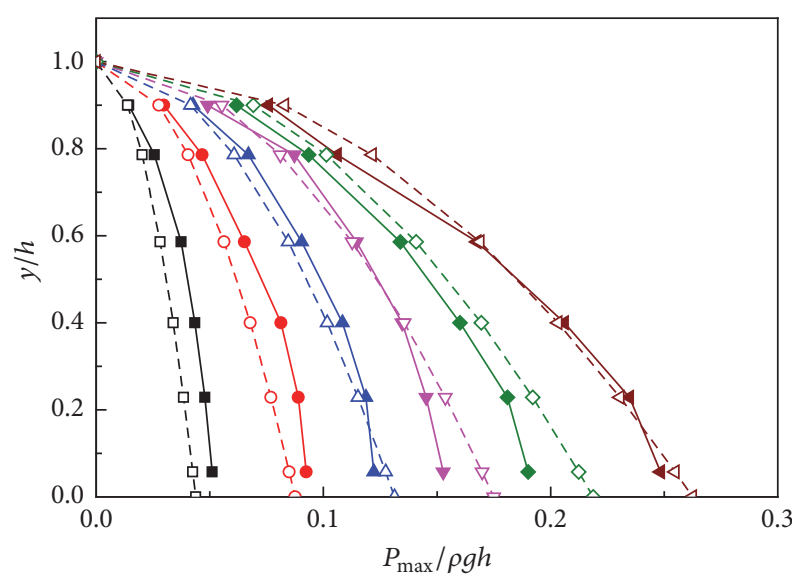

$$
\begin{aligned}
& \rightarrow 0.05 \mathrm{~g} \mathrm{EQ} 1 \text {, experimental } \\
& \neg-0.20 \text { g EQ1, experimental } \\
& -\square-0.05 \mathrm{~g} \text {, Westergaard } \\
& -\nabla-0.20 \mathrm{~g} \text {, Westergaard } \\
& -0.10 \mathrm{~g} \text { EQ1, experimental } \\
& \multimap 0.25 \mathrm{~g} \text { EQ1, experimental }
\end{aligned}
$$

FIGURE 7: Comparison of the maximum hydrodynamic pressures acting on the wall at the vertical face due to the Wolong earthquake waveform (EQ1): experimental results and Westergaard's formula.

Therefore, Figure 8 presents the hydrodynamic pressures recorded by sensors $\mathrm{P} i(i=1,2,3,4,5)$ with respect to time for EQ2 along with the $0.15 \mathrm{~g}$ acceleration data.

The results presented in Figure 8 indicate that the hydrodynamic pressure variations of EQ2 did not closely follow the seismic acceleration wave motion. The positive peak seismic acceleration was generated at $9 s-13 s$ while the corresponding positive peak hydrodynamic pressures were observed at $19 \mathrm{~s}-30 \mathrm{~s}$ for all sensors and exhibited some hysteresis. The development of the hydrodynamic pressure at sensor P1 with respect to time is examined over shorter time periods in Figure 9, indicating that the process can be divided into three stages. For $0<t<15 \mathrm{~s}$ in the segment denoted as (a), the fluctuations in the hydrodynamic pressure are initially similar to those of the seismic wave, and the amplitude increased with increasing time. For $15 \mathrm{~s}<t<30 \mathrm{~s}$ in the segment denoted as (b), the hydrodynamic pressure developed into a sine wave variation and maintained a fairly constant amplitude and steady period. For $t>30 \mathrm{~s}$ in the segment denoted as (c), the amplitude of the sine wave variation in the hydrodynamic pressure diminished because of the significant reduction in the excitation amplitude while approaching the completion of the EQ2 waveform. However, the amplitude required considerable time to decrease to zero after completion of the EQ2 waveform and did not attain a value of zero even after $250 \mathrm{~s}$ of monitoring, which is greater than five times the duration of the EQ2 waveform. Clearly, an excitation frequency close to the fundamental frequency of the water body resulted in a resonance phenomenon. In addition, the hydrodynamic pressure under conditions of resonance was significantly greater and the fluctuations far more stable than what was obtained from EQ1. The experimental data
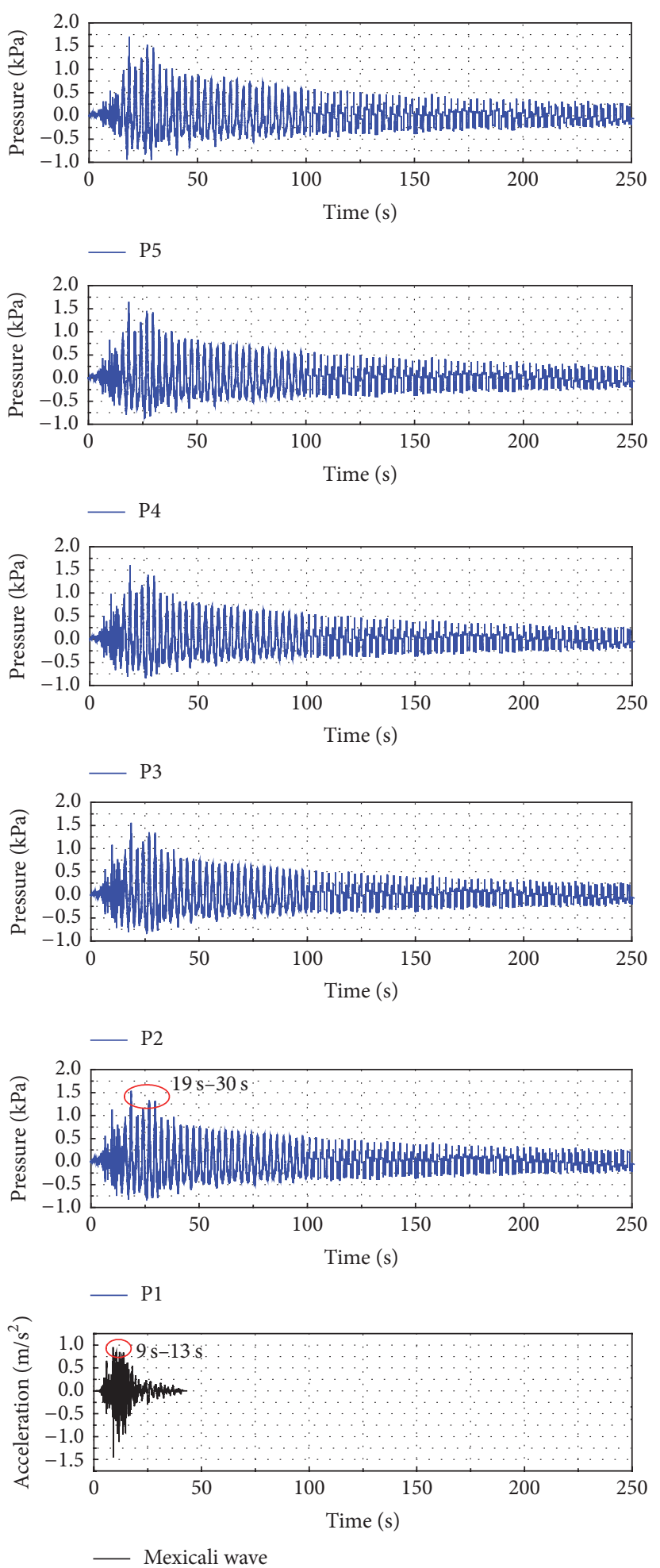

FIGURE 8: Fluctuations in the hydrodynamic pressures at sensors P1-P5 and the $0.15 \mathrm{~g}$ acceleration results with respect to time due to the Mexicali earthquake waveform (EQ2).

for the maximum hydrodynamic pressures obtained at the corresponding heights are listed in Table 2.

Figure 10 indicates that the distributions of the maximum hydrodynamic pressures with respect to the water height 


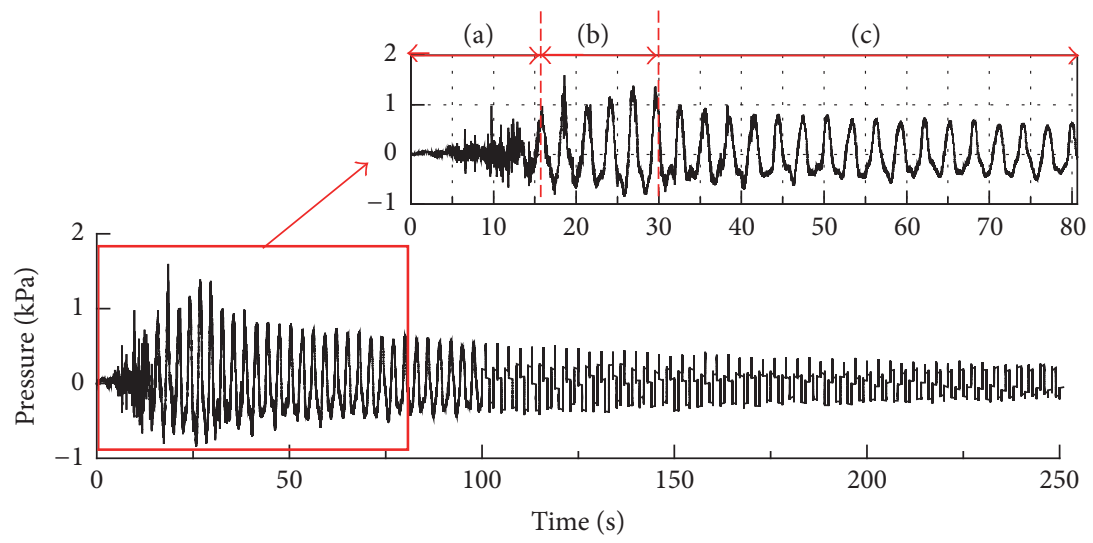

FIgURE 9: Hydrodynamic pressure variations at P1 due to EQ2.

TABLE 2: Maximum values of the hydrodynamic pressure due to the Mexicali earthquake waveform (EQ2).

\begin{tabular}{lccccccc}
\hline Number & \multirow{2}{*}{ Height $(\mathrm{cm})$} & 0.05 & 0.10 & 0.15 & 0.20 & 0.25 & 0.30 \\
\hline P1 & 2 & 0.231 & 0.453 & 0.831 & 1.296 & 1.543 \\
P2 & 8 & 0.223 & 0.452 & 0.83 & 1.303 & 1.562 & 1.8 \\
P3 & 14 & 0.207 & 0.448 & 0.83 & 1.329 & 1.599 & 1.83 \\
P4 & 20.5 & 0.182 & 0.44 & 0.845 & 1.372 & 1.653 \\
P5 & 27.5 & 0.152 & 0.413 & 0.792 & 1.394 & 1.702 & 1.867 \\
\hline
\end{tabular}

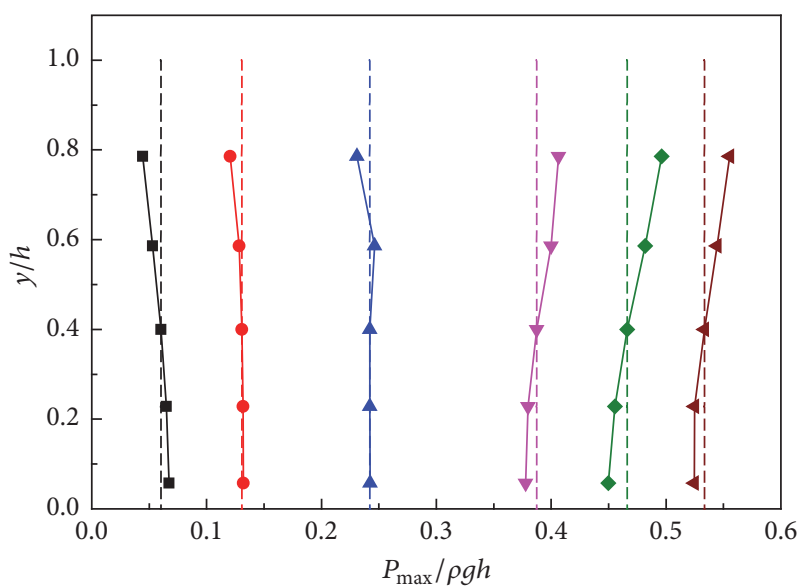

- 0.05 g EQ2, experimental

$\rightarrow 0.20 \mathrm{~g} \mathrm{EQ} 2$, experimental

$---0.10 \mathrm{~g}$, average

$--0.25 \mathrm{~g}$, average

$\neg 0.15 \mathrm{~g} \mathrm{EQ} 2$, experimental

- $-0.05 \mathrm{~g}$, average

$--0.20 \mathrm{~g}$, average

$\rightarrow 0.10 \mathrm{~g}$ EQ2, experimental

$\longrightarrow 0.25 \mathrm{~g} \mathrm{EQ} 2$, experimental

$\longleftarrow 0.30 \mathrm{~g} \mathrm{EQ} 2$, experimental

-- $0.15 \mathrm{~g}$, average

$---0.30 \mathrm{~g}$, average

FIGURE 10: Distributions of the maximum hydrodynamic pressures acting on the wall at the vertical face due to the Mexicali earthquake waveform (EQ2).

at equivalent PGA presented a uniform distribution under conditions of resonance. The uniform distributions obtained for EQ2 indicates equal impacting forces at each horizontal layer of the water body. The dashed lines represent the average values of the hydrodynamic pressures under different PGA, which were in particularly good agreement with the values measured by P3. Therefore, the measured pressures at P3 under different PGA were selected for further analysis of the hydrodynamic pressures and later employed to develop an empirical equation for hydrodynamic pressure under wave resonance conditions.

3.3. Comparison. For comparison, the hydrodynamic pressures obtained at different heights along the wall during excitation by EQ1 and EQ2 are presented in Figure 11 for PGA of $0.1 \mathrm{~g}, 0.2 \mathrm{~g}$, and $0.3 \mathrm{~g}$. Here, we note that the hydrodynamic pressures induced by EQ1 were significantly less than those induced by EQ2 at equivalent PGA owing to the larger hydrodynamic pressures induced under the wave resonance conditions of EQ2. And the distributions of the maximum hydrodynamic pressures with respect to the water height at equivalent PGA transformed from a parabolic distribution for EQ1 without resonance to a uniform distribution for EQ2 under conditions of resonance. Clearly, the Westergaard formula is not appropriate for estimating the maximum hydrodynamic pressure with wave resonance, which yield entirely different distributions of maximum hydrodynamic pressures.

Here, we would like to briefly discuss the effect of boundary interactions on the hydrodynamic pressure. For a nonresonant response, the works of Saini et al. [9], Aviles and Sanchez-Sesma [23], and Pelecanos et al. [16] indicated that the influence of finite reservoir dimensions is negligible for $L / h>5$. For the reservoir employed in the present experiments, $L / h=7.8$, which represents a semi-infinite 


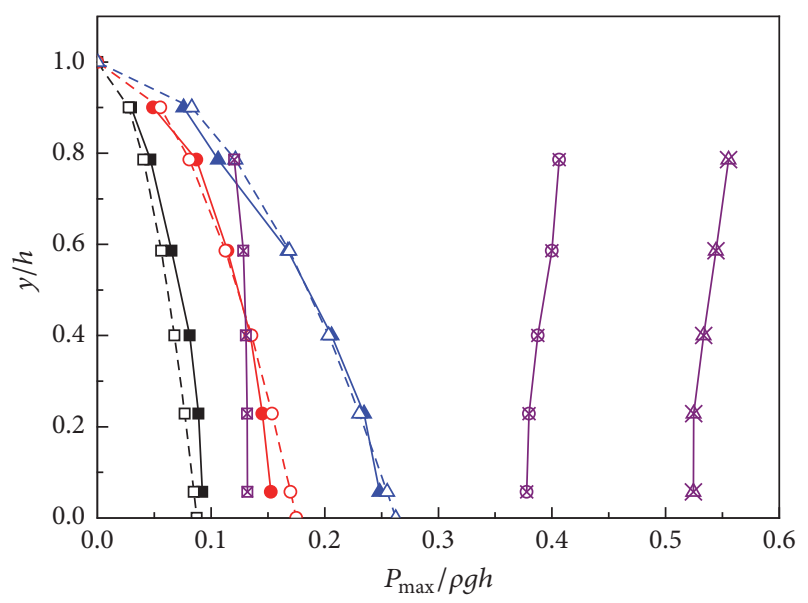

$$
\begin{aligned}
& \rightarrow 0.1 \mathrm{~g} \mathrm{EQ} 1 \text {, experimental } \\
& \text { - - } 0.1 \mathrm{~g} \text {, Westergaard } \\
& \text { ๑- } 0.1 \mathrm{~g} \mathrm{EQ} 2 \text {, experimental } \\
& \longrightarrow 0.2 \mathrm{~g} \text { EQ1, experimental } \\
& \text { - o- } 0.2 \mathrm{~g} \text {, Westergaard }
\end{aligned}
$$

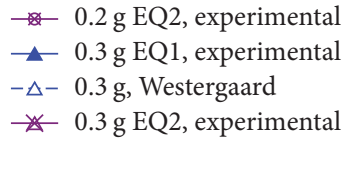

FIgURE 11: Comparison of the maximum hydrodynamic pressures on the wall at the vertical face due to waveforms EQ1 and EQ2: experimental and theoretical.

reservoir and is therefore not subject to the influence of reflection waves. During the resonant process, the influence of the reservoir dimensions was mainly reflected in the fundamental frequency of the reservoir, as demonstrated by (1). When the excitation frequency was close to the fundamental frequency of the water body, the water body presented regular wave motion of constant amplitude and tended to move as a whole. This suggests that the hydrodynamic pressures on the wall were not subject to downstream end effects under conditions of resonance.

3.4. Empirical Equation for Hydrodynamic Pressure with Wave Resonance. Without wave resonance, the hydrodynamic pressure coefficient $C_{p}$ is obtained from the following relationships $[1,6]$ :

$$
P_{\max }=C_{p} \rho a_{\max } h=C_{p} \rho k_{h} g h,
$$

where $a_{\max }$ is the PGA, $a_{\max }=k_{h} g$, and $k_{h}$ is the seismic acceleration coefficient in the horizontal direction. Based on the study of Westergaard, the hydrodynamic pressure loads exerted on the face of the dam can be represented as inertial forces like a certain part of the water as moving with the dam, of which that part was characterized as added mass [1], to define

$$
\int_{0}^{h} C_{p} \rho a_{\max } h d y=M a_{\max }
$$

where $M$ denotes the added mass. In this paper, following a consideration of the seismic frequency and water fundamental frequency by using a mass-spring model and assuming

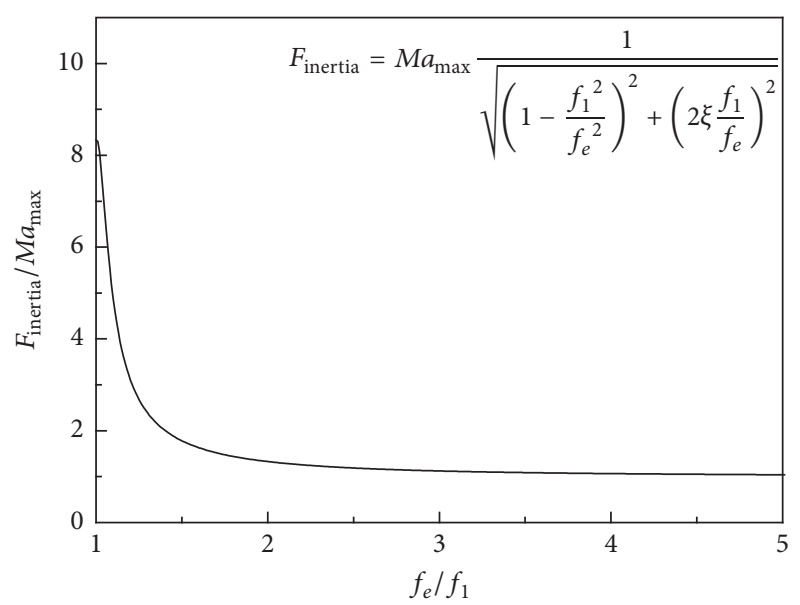

FIGURE 12: Relation between the ratio of the inertial force of the water $F_{\text {inertia }}$ and product of the added mass $M$ and maximum seismic acceleration $a_{\max }$ and the ratio of the seismic excitation frequency $f_{e}$ and fundamental frequency of the water body $f_{1}$.

equality between the maximum hydrodynamic pressure loads and the inertial force, the following equation is generated:

$$
\begin{aligned}
& \int_{0}^{h} C_{p} \rho a_{\max } h d y \\
& \quad=M a_{\max } \frac{1}{\sqrt{\left(1-f_{1}^{2} / f_{e}^{2}\right)^{2}+\left(2 \xi\left(f_{1} / f_{e}\right)\right)^{2}}} \\
& \quad=M a_{\max } \beta,
\end{aligned}
$$

where $f_{1}$ is the fundamental frequency of the water body, $f_{e}$ is the seismic excitation frequency, $\beta$ is the acceleration amplification coefficient, and $\xi$ is the damping ratio of this equivalent single degree of freedom (SDOF) system. An increase in the value of $\beta$ generates a stronger inertial force on the wall. The close relationship between the seismic excitation frequency and the hydrodynamic pressure is also outlined.

Figure 12 presents a plot of (5) presented above, where $F_{\text {inertia }}$ represents the inertial force of the water body on the wall. The work of Chopra has provided a simplified analysis method for determining the value of $\xi$ for a reservoir with rigid walls and foundation, which demonstrated that reservoir depth to wall height ratios $(h / H)$ from 0 to 1.0 provided a value of $\xi$ between 0.05 to 0.07 [24]. The present experiments employed $h / H=0.7$, such that Chopra's method generated a reasonable value of $\xi=0.06$. In general, a reservoir that is not completely empty or full will have a value of $\xi$ that can be approximated as 0.06 . For $f_{e}$ much greater than $f_{1}$, that is, $f_{1}^{2} / f_{e}^{2} \approx 0$, the water body exhibited steadystate movement that was synchronized to the seismic wave, such that $F_{\text {inertia }}$ was approximately equal to $M a_{\text {max }}$. The water body exhibited a small corresponding vibration amplitude, and the pressure amplitude exhibited enhanced attenuation. For $f_{e} \approx f_{1}$, that is, $f_{1}^{2} / f_{e}^{2} \approx 1$, the water body exhibited an increase in the corresponding vibration amplitude, which thereby resulted in an increased $F_{\text {inertia }}$ on the wall. Therefore, 
the effect of frequency is taken into consideration by the hydrodynamic pressure coefficient $\left(C_{p}^{\prime}\right)$, which is defined as

$$
\begin{aligned}
C_{p}^{\prime} & =C_{p} \beta, \\
\frac{P_{\max }}{\rho g h} & =C_{p}^{\prime} k_{h}=C_{p} \beta k_{h} .
\end{aligned}
$$

Westergaard [1] and Chwang and Housner [6] observed minimal effects on hydrodynamic pressures following changes in the frequency. Namely, the value $\beta \approx 1$ generates the following:

$$
\begin{aligned}
& \text { Westergaard's formula: } C_{p}^{\prime}=\frac{7}{8} \beta \sqrt{1-\frac{y}{h}} \approx \frac{7}{8} \sqrt{1-\frac{y}{h}} \\
& \quad=C_{p} \text {; } \\
& \text { Chwang's formula: } C_{p}^{\prime}=\frac{1}{\sqrt{2}} \beta \sqrt{1-\left(\frac{y}{h}\right)^{2}} \\
& \quad \approx \frac{1}{\sqrt{2}} \sqrt{1-\left(\frac{y}{h}\right)^{2}}=C_{p} .
\end{aligned}
$$

With wave resonance, the horizontal components of the inertial force of the water body were equivalent at each layer (Figure 10), which indicates that $C_{p}^{\prime}$ does not depend on the vertical location $(y / h)$. Therefore, the hydrodynamic pressure coefficient with wave resonance (denoted herein as $C_{p \text {-res }}$ ) can be expressed as

$$
\begin{aligned}
& C_{p-\text { res }}=C \beta, \\
& \frac{P_{\max }}{\rho g h}=C \beta k_{h}=\frac{C k_{h}}{\sqrt{\left(1-f_{1}^{2} / f_{e}^{2}\right)^{2}+\left(0.12\left(f_{1} / f_{e}\right)\right)^{2}}},
\end{aligned}
$$

where $C$ is a constant.

An empirical equation was developed according to (9) for the maximum hydrodynamic pressure with respect to the PGA under conditions of wave resonance based on the measured data at $\mathrm{P} 3$ generated by EQ2. In this paper, $f_{1}=$ $0.33 \mathrm{~Hz}$ and $f_{e}=0.38 \mathrm{~Hz}$, such that a linear fitting of the data of $P_{\max } / \rho g h$ versus $k_{h}$ for P3 yields a value of 0.466 for $C$ in (9) with a degree of fit indicated by $R^{2}=0.9573$. The resulting empirical expression is given as follows:

$$
\begin{aligned}
\frac{P_{\max }}{\rho g h} & =\frac{0.466 k_{h}}{\sqrt{\left(1-f_{1}^{2} / f_{e}^{2}\right)^{2}+\left(0.12\left(f_{1} / f_{e}\right)\right)^{2}}} \\
R^{2} & =0.9573 .
\end{aligned}
$$

The results shown in Figure 13 indicate that the maximum error is about $35 \%$ while most errors were less than $10 \%$. In the absence of good experimental data, the empirical equation given by (10) can be employed to estimate the maximum hydrodynamic pressure under conditions of wave resonance.

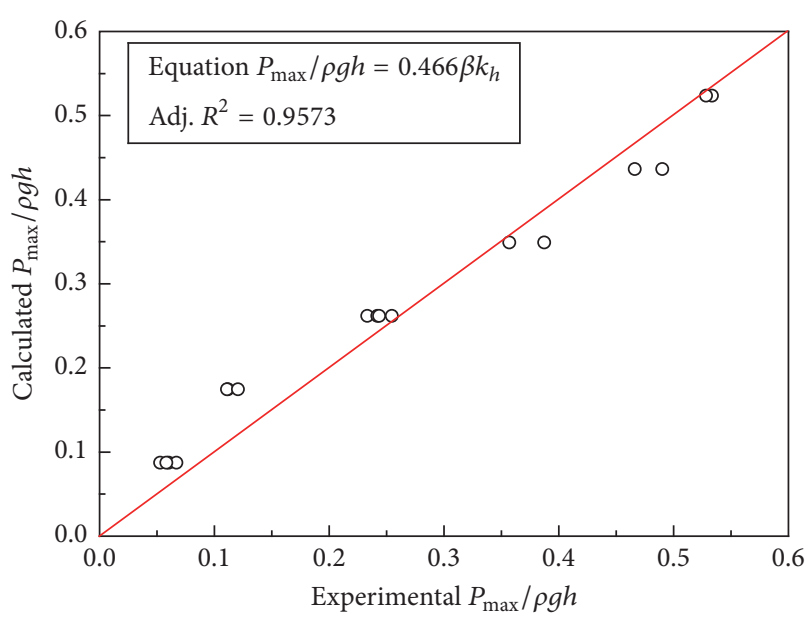

FIGURE 13: A comparison of the calculated values obtained from a linear fit of the experimental hydrodynamic pressure data at P3 for EQ2.

3.5. Discussion. In the present study, the experiments only considered the distribution of hydrodynamic pressures on a rigid wall with a vertical face. In reality, the upstream face of a natural dam is irregular. Therefore, the variations in the hydrodynamic pressures under conditions of resonance will be more complex. Additionally, the present study only considered the homodromous movement of seismic waves. Different seismic wave directions must be considered in future studies to understand the failure mechanisms of moraine dams.

\section{Conclusions}

The characteristics of seismic-induced hydrodynamic pressures acting on a vertical wall face were experimentally investigated using a shaking table. Two seismic waveforms, EQ1 and EQ2, were utilized to obtain different hydrodynamic pressures under equivalent conditions, where the dominant frequency of EQ1 was much greater than the fundamental frequency of the water body employed in the experiments (i.e., no resonance) and that of EQ2 was nearly equivalent to the fundamental frequency (i.e., with resonance). The experimental results were employed to develop an empirical equation to predict the maximum hydrodynamic pressure under conditions of wave resonance. The following conclusions were generated.

(1) In the case of nonresonance, the hydrodynamic pressure variation significantly followed the seismically accelerated wave motion, and the experimental pressure values were in good agreement with corresponding hydrodynamic pressures determined by Westergaard's equation. However, the fluctuations in the hydrodynamic pressure observed under conditions of resonance were similar to the variations of a sine wave, and the positive peak values exhibited some hysteresis. Conditions of wave resonance produced larger hydrodynamic pressure values and much longer periods of increased hydrodynamic pressure than the case of nonresonance, which obviously poses a greater threat to the stability of dams. 
(2) The effect of the seismic excitation frequency and the fundamental frequency of the reservoir on the maximum hydrodynamic pressure was analyzed from the standpoint of a mass-spring model. The maximum hydrodynamic pressures on the vertical wall under conditions of resonance exhibited a uniform distribution rather than the parabolic distribution obtained without resonance. The experimentally obtained maximum hydrodynamic pressures under conditions of resonance were linearly fitted to an analytically derived expression to obtain an empirical equation for predicting the maximum hydrodynamic pressure with wave resonance. An $R^{2}$ value of 0.9573 was obtained, which, to the best of our knowledge, represents a reasonable degree of accuracy for estimating the maximum pressure.

(3) Based a theoretical formula calculation [22], a small reservoir range, which had a length less than $100 \mathrm{~m}$ and a depth less than $20 \mathrm{~m}$, exhibited a fundamental frequency between $0.1 \mathrm{~Hz}$ and $1 \mathrm{~Hz}$. However, the seismic wave spectrum exhibited a wider range than the small reservoir spectrum. Hence, an assessment of the outburst risk of such a small lake in seismic zones must consider the wave resonance caused by earthquakes as a security practice, particularly in far-field earthquake regions where the seismic amplitudes are reduced. However, these spectrums are mainly composed of low frequencies. Ultimately, the effect of wave resonance must not be neglected.

(4) The issue of seismic-induced wave resonance was mainly characterized by relatively large hydrodynamic pressure. During the propagation of the seismic surge wave, the surge wave lashed against the wall of the reservoir such that the run-up wave height became a key parameter. The wave continued to propagate and erode, thereby forming an outflow channel. The surge wave also affected the stability of the dam and could significantly impact the lives and property of residents along the shore. Therefore, quantification of the seismic surge wave height is a further issue that requires rigorous characterization and further investigation.

\section{Conflicts of Interest}

The authors declare that there are no conflicts of interest regarding the publication of this paper.

\section{Acknowledgments}

This work is financially supported by the Natural Science Foundation of China under Contract no. 41571004; Scientific and Technological Research and Development Plan of China Railway Corporation (no. 2015G002-N); and Natural Science Foundation of China (no. 41172321). The authors express their gratitude to these foundations. The authors acknowledge LetPub for their linguistic assistance during the preparation of this manuscript.

\section{References}

[1] H. M. Westergaard, "Water pressures on dams during earthquakes," Transactions of the American Society of Civil Engineers, vol. 98 , no. 3, pp. 418-433, 1933.
[2] D. Zou, Y. Zhou, H. I. Ling, X. Kong, and B. Xu, "Dislocation of face-slabs of Zipingpu concrete face rockfill dam during Wenchuan earthquake," Journal of Earthquake and Tsunami, vol. 6, no. 2, Article ID 1250007, 2012.

[3] D. Chakraborty and D. Choudhury, "Sliding stability of nonvertical waterfront retaining wall supporting inclined backfill subjected to pseudo-dynamic earthquake forces," Applied Ocean Research, vol. 47, pp. 174-182, 2014.

[4] D. Chakraborty and D. Choudhury, "Stability of non-vertical waterfront retaining wall supporting inclined backfill under earthquake and tsunami," Ocean Engineering, vol. 78, pp. 1-10, 2014.

[5] C. N. Zangar, "Hydrodynamic pressures on dams due to horizontal earthquakes," Proceedings of the Society for Experimental Stress Analysis, vol. 10, pp. 93-102, 1953.

[6] A. T. Chwang and G. W. Housner, "Hydrodynamic pressures on sloping dams during earthquakes. Part 1. Momentum method," Journal of Fluid Mechanics, vol. 87, no. 2, pp. 335-341, 1978.

[7] A. T. Chwang, "Hydrodynamic pressures on sloping dams during earthquakes. Part 2. Exact theory," Journal of Fluid Mechanics, vol. 87, no. 2, pp. 343-348, 1978.

[8] M. M. Wang, J. Y. Chen, and Q. Xu, "Study on different height gravity hydrodynamic pressure and westergaard correction formula," Engineering Mechanics, vol. 30, no. 12, pp. 65-70, 2013.

[9] S. S. Saini, P. Bettess, and O. C. Zienkiewicz, "Coupled hydrodynamic response of concrete gravity dams using finite and infinite elements," Earthquake Engineering \& Structural Dynamics, vol. 6, no. 4, pp. 363-374, 1978.

[10] M. Zingales, "Seismically induced, non-stationary hydrodynamic pressure in a dam-reservoir system," Probabilistic Engineering Mechanics, vol. 18, no. 2, pp. 151-163, 2003.

[11] N. Bouaanani, P. Paultre, and J. Proulx, "A closed-form formulation for earthquake-induced hydrodynamic pressure on gravity dams," Journal of Sound and Vibration, vol. 261, no. 3, pp. 573582, 2003.

[12] I. Gogoi and D. Maity, "A novel procedure for determination of hydrodynamic pressure along upstream face of dams due to earthquakes," Computers and Structures, vol. 88, no. 9-10, pp. 539-548, 2010.

[13] X. B. Chen and S. Malenica, "Hydrodynamic pressure distribution on ship hull at very high encounter frequencies," Journal of Hydrodynamics, vol. 22, no. 5, pp. 515-520, 2010.

[14] S. Saleh and S. P. G. Madabhushi, "An investigation into the seismic behaviour of dams using dynamic centrifuge modelling," Bulletin of Earthquake Engineering, vol. 8, no. 6, pp. 1479-1495, 2010.

[15] S. Saleh and S. P. G. Madabhushi, "Response of concrete dams on rigid and soil foundations under earthquake loading," Journal of Earthquake and Tsunami, vol. 4, no. 3, pp. 251-268, 2010.

[16] L. Pelecanos, S. Kontoe, and L. Zdravković, "Numerical modelling of hydrodynamic pressures on dams," Computers and Geotechnics, vol. 53, pp. 68-82, 2013.

[17] L. Pelecanos, S. Kontoe, and L. Zdravković, "Dam-reservoir interaction effects on the elastic dynamic response of concrete and earth dams," Soil Dynamics and Earthquake Engineering, vol. 82, pp. 138-141, 2016.

[18] H. Xu, D. Zou, X. Kong, and Z. Hu, "Study on the effects of hydrodynamic pressure on the dynamic stresses in slabs of high CFRD based on the scaled boundary finite-element method," Soil Dynamics and Earthquake Engineering, vol. 88, pp. 223-236, 2016. 
[19] B.-F. Chen and Y.-S. Yuan, "Hydrodynamic Pressures on Arch Dam during Earthquakes," Journal of Hydraulic Engineering, vol. 137, no. 1, pp. 34-44, 2011.

[20] E. W. Graham and A. M. Rodriguez, "The characteristics of fuel motion which affect airplane dynamics," Journal of applied mechanics, vol. 19, no. 03, pp. 381-388, 1952.

[21] G. W. Housner, "Earthquake Pressures on Fluid Containers," Eight Technical Report under Office of Naval Research, California Institute of Technology, Pasadena, CA, USA, 1954.

[22] G. X. Wu, Q. W. Ma, and R. Eatock Taylor, "Numerical simulation of sloshing waves in a 3D tank based on a finite element method," Applied Ocean Research, vol. 20, no. 6, pp. 337355, 1998.

[23] J. Aviles and F. J. Sanchez-Sesma, "Water pressures on rigid gravity dams with finite reservoir during earthquakes," Earthquake Engineering \& Structural Dynamics, vol. 18, no. 4, pp. 527-537, 1989.

[24] G. Fenves and A. K. Chopra, "Simplified earthquake analysis of concrete gravity dams," Journal of Structural Engineering (United States), vol. 113, no. 8, pp. 1688-1708, 1987. 


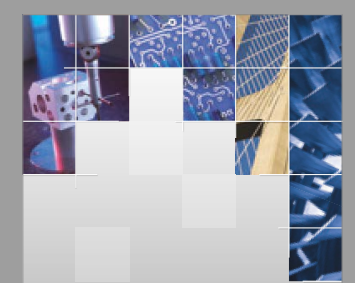

\section{Enfincering}
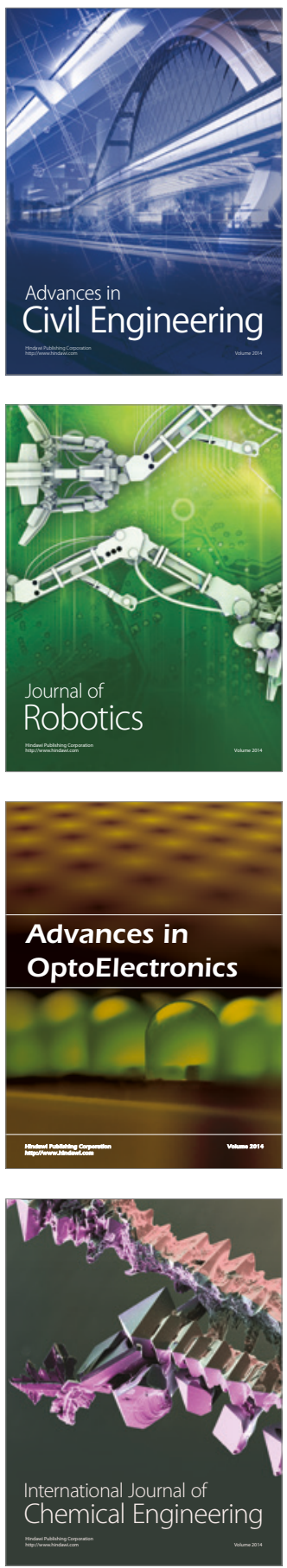

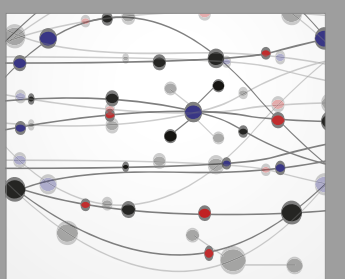

The Scientific World Journal

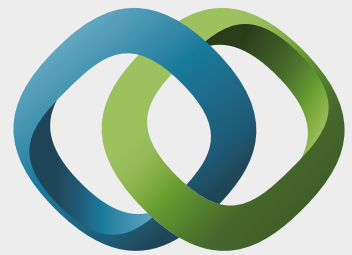

\section{Hindawi}

Submit your manuscripts at

https://www.hindawi.com
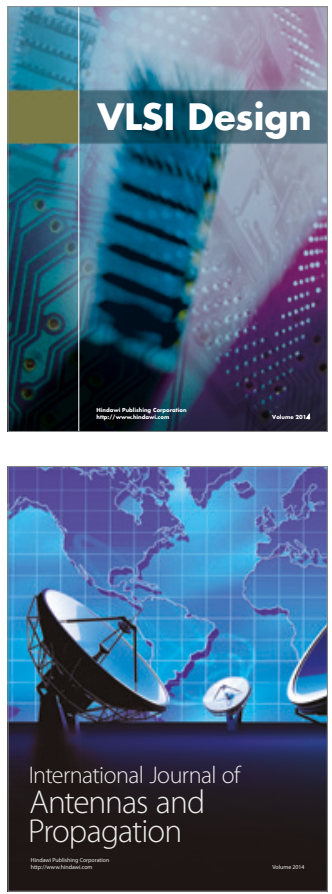

\section{Rotating}

Machinery
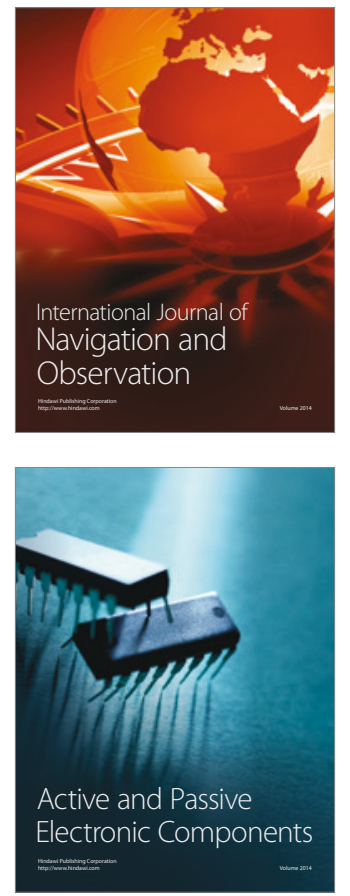
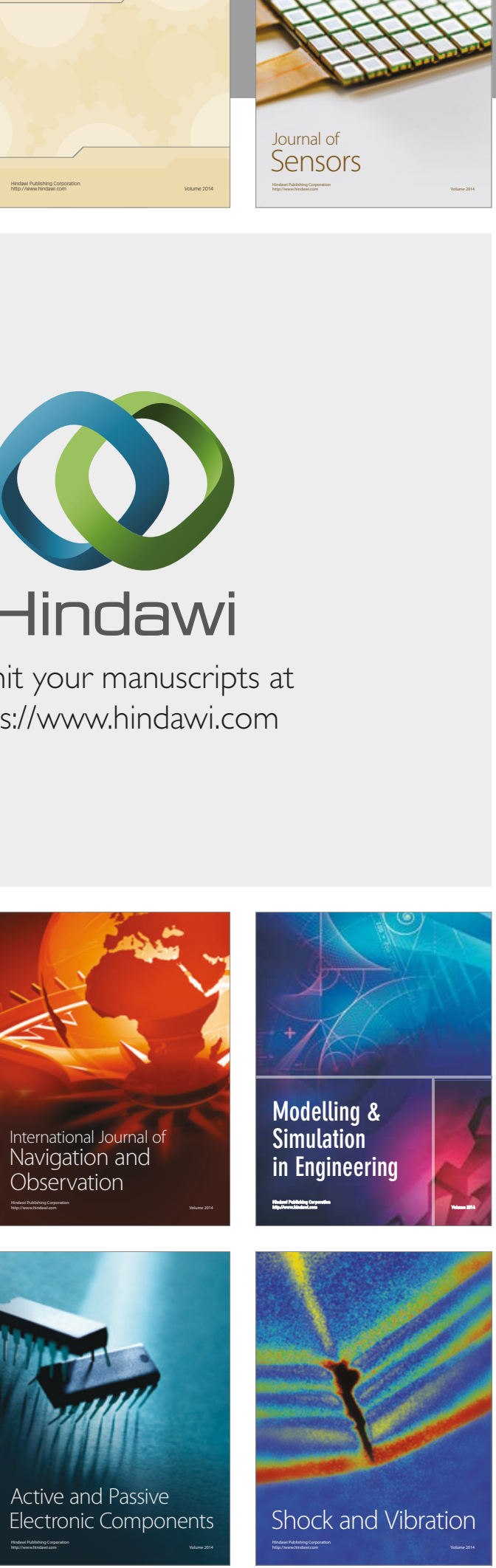
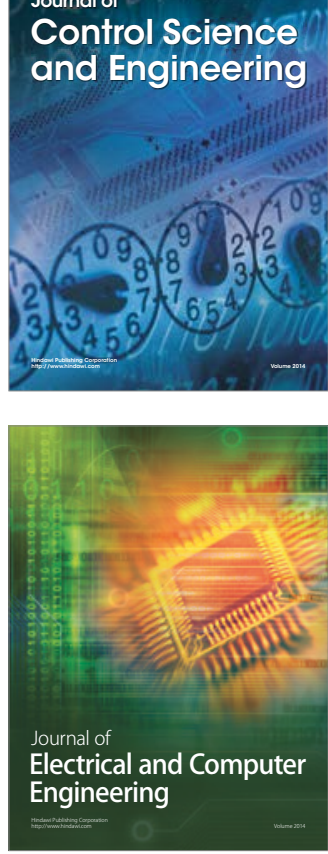

Distributed

Journal of

Control Science

and Engineering
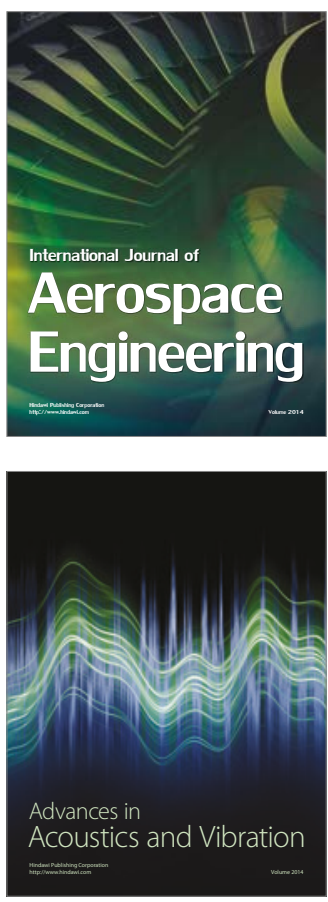

Sensor Networks 